of CS using VF as a marker for maternal obesity and to compare it with Body Mass Index (BMI) as a predictor.

Women were recruited following ultrasound confirmation of a singleton first trimester pregnancy. Maternal VF was measured using Bioelectrical Impedance Analysis (BIA). Maternal BMI was measured. Data was analysed using SPSS.

Of the 3000 women recruited, 2825 women subsequently delivered a baby weighing $>500$ g. There were $45.9 \%$ primigravidas and $17.6 \%$ were obese. The CS rate was $21.4 \%$. VF in the $3^{\text {rd }}$ and $4^{\text {th }}$ quintiles was associated with an odds ratio for CS of 1.6 (95\% CI 1.3-2.1) and $2.2(95 \%$ CI $1.7-2.9)$ respectively $(p<0.001)$. BMI in the $3^{\text {rd }}$ and $4^{\text {th }}$ quintiles was associated with an OR for CS of 1.5 (95\% CI 1.2-2.0) and 2.3 (95\% CI 1.7-3.3) respectively ( $p<0.001)$. After controlling for parity, previous CS and birth weight the ORs were 1.8 (95\% CI 1.3$2.4)$ and $2.3\left(95 \%\right.$ CI 1.7-2.1) for the $3^{\text {rd }}$ and $4^{\text {th }}$ quintiles for VF $(\mathrm{p}<0.001)$. The adjusted ORs for CS were 1.6 (95\% CI 1.2-2.3) and 2.4 (95\% CI 1.7-3.4) when the $3^{\text {rd }}$ and $4^{\text {th }}$ quintiles for BMI were used.

Maternal obesity is associated with an increased risk of CS. Maternal adiposity measured by BIA is as good a predictor of the risk of CS as BMI.

\section{PL.38 RECURRENCE RATE OF THIRD DEGREE PERINEAL TEARS AT ST MICHAEL'S HOSPITAL}

doi:10.1136/archdischild-2013-303966.221

\section{Davies, R Bahl. Univeristy Hospitals Bristol NHS Trust, Bristol, UK}

Introduction A number of risk factors for third and fourth degree perineal tears or obstetric anal sphincter injury (OASI) have been identified, but the rate of recurrence is not consistent in the observational studies.

Aim To assess the rate of third degree tear following an OASI in the first pregnancy in a tertiary referral unit.

Methods Data was collected from maternity database, for women diagnosed with an OASI in their first pregnancy who went on to have a subsequent pregnancy at St. Michael's hospital. Data collection period was between 2007-2012. Data was limited to term, singleton, cephalic deliveries in subsequent pregnancy.

Results 210 women met the criteria. 63 (30\%) had an elective caesarean section and 147 (70\%) opted for vaginal delivery. 10/147 (6.8\%) required an emergency LSCS. 14/137 (10.2\%) women who had a vaginal delivery sustained a further OASI. When comparing the women who had OASI to women who did not sustain an OASI in the subsequent pregnancy, there was no significant difference between the mean birth weights or the mode of onset of labour. Conclusion Over the five year period the recurrence risk of OASI was low. This information can be used to advise women when discussing mode of delivery in subsequent pregnancies. Further research is needed into the pelvic floor symptom profile of the women who have a vaginal birth following an OASI in the first pregnancy.

\section{PL.39 INCIDENCE AND RISK FACTORS FOR SEVERE PPH: A PROSPECTIVE SOUTH EAST COHORT STUDY (STOP)}

doi:10.1136/archdischild-2013-303966.222

'A Briley, ${ }^{2 G}$ Tydeman, ${ }^{3 P T}$ Seed, ${ }^{3} \mathrm{H}$ Ballard, ${ }^{3} \mathrm{~J}$ Sandall, ${ }^{3} \mathrm{RM}$ Tribe, ${ }^{3} \mathrm{~S}$ Bewley. ${ }^{1} \mathrm{Guy}$ 's and St Thomas' NHS Foundation Trust, London, UK; ${ }^{2} N H S$ Fife, Kirkcaldy, UK; ${ }^{3} K i n g$ 's College, London, London, UK

Introduction Postpartum haemorrhage $(\mathrm{PPH})$ is common, rising and treatable (1). Most women are not compromised until estimated blood loss (EBL) exceeds $1000 \mathrm{ml}$ (2). Major PPH remains a cause of maternal death (3) but definitions vary, making comparisons difficult. The Scottish population-based annual audit reported $0.55 \%$ incidence of $\mathrm{PPH} \geq 2500 \mathrm{ml}$, the highest since inception (4).

Aims To ascertain the incidences of severe PPH defined as EBL $\geq 1000 \mathrm{ml}, \geq 1500 \mathrm{ml}$ and $\geq 2500 \mathrm{ml}$ in a prospective cohort from
South East England. To determine risk factors associated with EBL at, and progressing from, these levels.

Methods Routine data were imported from 10,213 women delivering in two units 2008-9. All cases with imported EBL $\geq 1000 \mathrm{ml}$ and/ or identified via blood transfusion services were reviewed. Weighted sampling and chronological stepwise regression analysis were performed. Incidence was compared historically (same geographical population 1997-8) and contemporaneously (Scottish Audit 2009). Results Incidenc es of $\mathrm{PPH} \geq 1000 \mathrm{ml}, \geq 1500 \mathrm{ml}$ and $\geq 2500 \mathrm{ml}$ were $10.1 \%$ (95\%CI 4.8-6.0), 4.7\% (95\%CI 3.3-6.1) and 0.8\% (95\%CI 0.61.0) respectively. Historical rate of $\mathrm{PPH} \geq 1500 \mathrm{ml}=1.12 \%(95 \% \mathrm{CI}$ $0.92-1.38$ ). Contemporaneous $\mathrm{PPH} \geq 2500 \mathrm{ml}$ was $0.55 \%$ (95\%CI 0.5 to 0.6). Risk factors for severe PPH included BMI, generally unwell without diagnosis, anterior placenta praevia, chorioamnionitis, no labour, physiological $3^{\text {rd }}$ stage of labour and interval to suturing. Previous, elective and emergency caesarean section were protective.

Conclusions Severe PPH rates are rising rapidly. These demonstrated are comparable with contemporaneous UK data. Risk factors for PPH and severe PPH differ. The underlying causes originate pre-pregnancy, through pre-exisiting health status and previous obstetric history, some are associated with quality of care.

\section{REFERENCES}

1. Knight M, Knight M, Callaghan WM et al, Trends in postpartum haemorrhage in high resource countries: a review and recommendations from the International Postpartum Hemorrhage Collaborative Group. BMC Pregnancy \& Childbirth 2009; 9.

2. Brace V, Penney G, Hall M. Quantifying severe maternal morbidity: a Scottish population study. BJOG 2004: 111(5):481-4.

3. CMACE Saving mothers' Lives. BJOG 2011;118:1-203.

4. Scotland Health Improvement. Scottish Confidential Audit of Severe Maternal Morbidity $7^{\text {th }}$ Annual Report 2011.

\section{PL.40 ACCESS TO OBSTETRIC SERVICES IN RURAL SUB-SAHARAN AFRICA: A HOSPITAL BASED SURVEY}

doi:10.1136/archdischild-2013-303966.223

'RE Harris, ' 'LM Staffurth, 'L Irvine, 'NL Hezelgrave, ${ }^{2}$ S Edmunds, ${ }^{1}$ AH Shennan. 'Division of Women's Health KCL, Women's Health Academic Centre, KHP, London, UK; ${ }^{2} H o s p i t a l i$ Teule, Muheza, United Republic of Tanzania

Background Access to Emergency Obstetric Care (EmOC) is an indicator used to monitor progress towards the achievement of Millennium Development Goals 4 and 5. Lack of access or delay in transportation to hospital is recognised as part of 'The Three Delays Model' and is a major barrier to accessing care for pregnant women living in rural Sub-Saharan Africa.

Objective To determine time taken (minutes) by any mode of transport, to reach an obstetric facility by pregnant women in Zambia, Tanzania and Zimbabwe.

Methods A structured questionnaire in Swahili was used to interview pregnant women from $20-42$ weeks gestation who presented to hospital.

Results 750 women were interviewed on the labour ward and antenatal clinics in referral hospitals served by rural antenatal clinics in Zambia $(\mathrm{N}=128)$, Tanzania $(\mathrm{N}=246)$ and Zimbabwe $(\mathrm{N}=376)$. Median gestation was 33.4 weeks $(\mathrm{N}=681) .38 .8 \%$ were primiparous $(\mathrm{N}=614)$. The mean time taken to get from home to obstetric care was 48.3 minutes ( $I O R=15-60$, median 30$)$. The most common mode of transport was bus (40.6\%), followed by foot $(30.7 \%)$, car $(19.3 \%)$, bike $(9.0 \%)$ and other $(0.4 \%)(\mathrm{N}=512)$.

Conclusion In a sample population of antenatal women who successfully reached the referral site during dry season, average time taken to travel from home to hospital was $>48$ minutes. In the wet season and for women in remote rural areas, this is likely to be higher. On foot, during an obstetric emergency, this may represent a significant delay. It is vital that maternal health interventions are designed to address this.

Funder Bill Gates Foundation Grand Challenges Explorations (GCE). 